\title{
BMJ Open Association between occupational physical activity and myocardial infarction: a prospective cohort study
}

\author{
Anna M Johnsen, ${ }^{1}$ Lars Alfredsson, ${ }^{2,3}$ Anders Knutsson, ${ }^{4}$ Peter J M Westerholm, ${ }^{5}$ \\ Eleonor I Fransson ${ }^{1,2}$
}

To cite: Johnsen AM, Alfredsson L, Knutsson A, et al. Association between occupational physical activity and myocardial infarction: a prospective cohort study. BMJ Open 2016;6:e012692. doi:10.1136/bmjopen-2016012692

- Prepublication history and additional material is available. To view please visit the journal (http://dx.doi.org/ 10.1136/bmjopen-2016012692)

Received 31 May 2016 Revised 13 September 2016 Accepted 14 September 2016 CrossMark

${ }^{1}$ Department of Natural Science and Biomedicine, School of Health and Welfare, Jönköping University, Jönköping, Sweden

${ }^{2}$ Institute of Environmental Medicine, Karolinska Institutet, Stockholm, Sweden

${ }^{3}$ Centre for Occupational and Environmental Medicine, Stockholm County Council, Stockholm, Sweden

${ }^{4}$ Department of Health Sciences, Mid Sweden University, Sundsvall,

Sweden

${ }^{5}$ Occupational and

Environmental Medicine,

Uppsala University, Uppsala, Sweden

Correspondence to Anna M Johnsen; anna.johnsen@ju.se

\section{ABSTRACT}

Objective: Recommendations regarding physical activity typically include both leisure time and occupational physical activity. However, the results from previous studies on occupational physical activity and the association with myocardial infarction have been inconsistent. The aim of this study was to investigate if occupational physical activity is associated with the risk of myocardial infarction.

Design: Prospective cohort study.

Participants: Data from the Swedish Work, Lipids and Fibrinogen (WOLF) study was used, comprising 9961 employees (6849 men, 3112 women, mean age 42.7 years) having no history of myocardial infarction. The participants were categorised into 3 groups according to their level of occupational physical activity.

Outcome: Data regarding incident myocardial infarction were obtained from the Swedish National Patient Register and the Cause of Death Register. Cox proportional hazard regression was used for estimation of HRs for different levels of occupational physical activity in relation to the risk of myocardial infarction.

Results: During a mean follow-up of 13.1 years, 249 cases of incident myocardial infarction were identified. In analyses adjusted for age, sex and socioeconomic status, participants standing and walking more than $50 \%$ of their working day had an HR of $1.13(95 \% \mathrm{Cl} 0.83$ to 1.54$)$, compared with participants seated more than $50 \%$ of their working day. The corresponding HR for participants whose work included lifting or carrying was 0.86 (95\% $\mathrm{Cl} 0.59$ to 1.24). Further adjustment did not alter the results. Stratified analyses resulted in a significantly decreased risk for young people whose work included lifting or carrying, HR 0.37 ( $95 \% \mathrm{Cl} 0.17$ to 0.84 ), compared with younger persons who sat most of their working day.

Conclusions: No significant association between occupational physical activity and the risk of myocardial infarction was observed in the total group of employees in this study. Based on the results from this study, occupational physical activity in general does not seem to be enough for reducing the risk of myocardial infarction.

\section{INTRODUCTION}

Ischaemic heart disease is the leading cause of global mortality and burden of disease. In

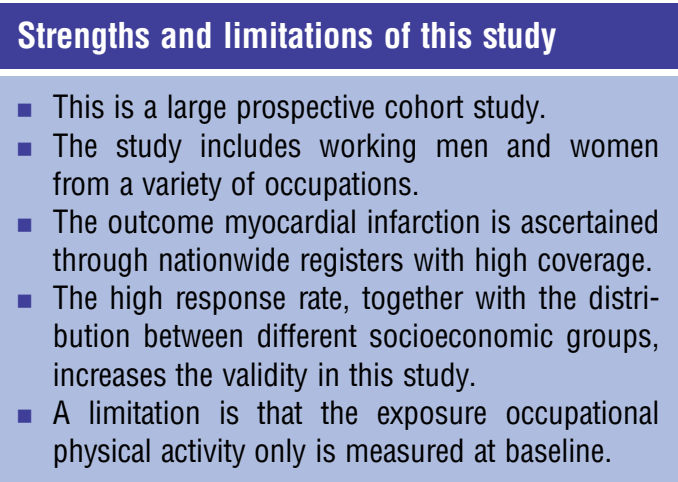

2010 , more than $13 \%$ of all deaths were due to ischaemic heart disease. ${ }^{12}$ Physical activity is known as a preventive factor for ischaemic heart disease. ${ }^{3-6}$ However, the term physical activity is general and may involve leisure time physical activity, occupational physical activity, commuting and household chores. ${ }^{7}$ In more recent research, a distinction is often made between leisure time physical activity and occupational physical activity. The findings regarding leisure time physical activity are quite consistent that high levels of physical activity decrease the risk of cardiovascular disease (CVD).$^{8-12}$ In contrast, studies of occupational physical activity and CVD show more inconsistent results, where some studies have shown that high occupational physical activity increases the risk of CVD, ${ }^{11}{ }^{13-15}$ while other results point towards a protective effect of moderate-tohigh occupational physical activity. ${ }^{10} 1617$ In the recommendations from the WHO regarding physical activity, both leisure time physical activity and occupational physical activity are included, without distinction in the recommendations regarding these different domains of physical activity. ${ }^{18}$

The aim of this study was to investigate if occupational physical activity in terms of standing/walking and lifting/carrying at 
work is associated with the risk of myocardial infarction and if the association is modified by age, sex, socioeconomic status and leisure time physical activity. In line with the recommendations from the WHO regarding physical activity in general, the hypothesis in this study was that occupational physical activity has a protective effect against myocardial infarction.

\section{METHODS}

Data used for this study were obtained from the Swedish Work, Lipids and Fibrinogen (WOLF) study. ${ }^{19}$ Participants were included for the baseline data collection in 1992-1995 in Stockholm County and in 19961997 in the counties of Jämtland and Västernorrland. Occupational health service units were invited to participate in the study; 33 of the 36 accepted the invitation. These units served employees from around 60 different companies in several different branches and occupations. The employees who were willing to participate filled in a questionnaire including questions regarding their occupation and work environment, socioeconomic factors, lifestyle factors, hereditary factors and disease history. In addition, the employees went through a clinical examination including measurements of blood pressure, height, weight, waist and hip circumference. In total, 10416 employees responded to the questionnaire and went through the clinical examination. The response rate was $82 \%$ for the total sample, with higher response rates in Jämtland and Västernorrland, compared with the Stockholm area.

\section{Occupational physical activity}

The participants were asked about their occupational physical activity (OPA) by three questions in the questionnaire: (1) whether or not they were seated for more than half of their total working hours; (2) if they were lifting or carrying more than $5 \mathrm{~kg}$ for at least 2 hours of their working day and (3) for women, if they were lifting or carrying more than $20 \mathrm{~kg}$ at least five times per working day. For men, the corresponding question was if they were lifting or carrying more than $30 \mathrm{~kg}$ at least five times per working day.

Out of these three questions, the participants were categorised into three groups: seated for more than half of their working day and no lifting or carrying (OPA 1); standing or walking for more than half of their working day but with no lifting or carrying (OPA 2); lifting or carrying either $5 \mathrm{~kg}$ for at least 2 hours of their working day, or heavy lifting (20 kg for women and $30 \mathrm{~kg}$ for men) at least five times per working day, regardless of whether they were seated or standing/walking most of their working day (few were lifting/carrying and were seated most of their working day) (OPA 3).

\section{Myocardial infarction}

Data regarding incident myocardial infarction were obtained from the National Patient Register and the
Cause of Death Register, using the diagnosis 'acute myocardial infarction', I21 International Classification of Diseases, 10th Revision (ICD-10) or 410 (ICD-9).

\section{Potential confounders}

Since several factors, such as age, sex, socioeconomic status, smoking, leisure time physical activity, alcohol and consumption of fruit and vegetables, might be associated with both occupational physical activity and the risk of myocardial infarction, these were taken into account in the analyses. Age was used as a continuous variable in all analyses except when stratifying the analysis by age, where the participants were categorised into three different groups: (1) younger than 45 years; (2) 45-54 years; (3) 55 years or older. Socioeconomic status was defined from the Swedish socioeconomic classification, ${ }^{20}$ according to the participants' occupation and education. From this classification, the participants were categorised into three different socioeconomic groups: (1) manual workers; (2) low and intermediate nonmanual workers; (3) professionals. The participants were categorised into three groups regarding their smoking habits at baseline: never smoked, former smokers or current smokers. The participants were asked about their leisure time physical activity by the question 'How often do you exercise?'. The response options were 'never', 'very seldom', 'sometimes' and 'regularly'. In the analyses, the participants were categorised into three groups where the two least active answers were combined into one group: (1) never or seldom; (2) sometimes and (3) regularly. The participants were categorised into two groups regarding their consumption of fruit and vegetables: whether or not they were eating at least one piece of fruit every day, and whether or not they were eating one portion of vegetables every day. The participants were asked about their average alcohol consumption during the past 12 months. On the basis of this question, the participants were classified into four categories: (1) non-drinking; (2) moderate drinking; (3) intermediate drinking and (4) heavy drinking. Moderate drinking was defined as drinking 121 units of alcohol per week (men), or 1-14 units per week (women). Intermediate drinking was defined as drinking 22-27 units of alcohol per week (men), or 1520 units per week (women). Heavy drinking was defined as drinking 28 units of alcohol or more per week (men), or 21 units or more per week (women). One unit of alcohol is approximately equivalent to $10 \mathrm{~g}$ of ethanol.

\section{Statistical analysis}

In this prospective cohort study, participants without any history of myocardial infarction at baseline were followed from inclusion date (the day of their clinical examination) until their first myocardial infarction event, migration out of Sweden, death or end of follow-up (31 December 2008), whichever came first. Data on incidence of myocardial infarction before baseline were obtained from the respondent's disease history in the 
questionnaire, or from data in the National Patient Register. Data on migration were obtained from the Swedish Tax Agency.

In the present study, 93 participants with a history of myocardial infarction prior to the inclusion date were excluded. Students $(n=113)$, and one participant who emigrated from Sweden before the inclusion date $(n=1)$, were also excluded. Participants with missing answers in one or more of the questions regarding physical activity at work $(n=248)$ could not with certainty be categorised in one of the three categories of occupational physical activity and were therefore excluded. In total, this yielded an analytical sample for this study of $n=9961$.

Cox proportional hazard regression was used for estimation of HRs, with 95\% CIs, for different levels of occupational physical activity in relation to the risk of myocardial infarction. Multivariable regression models included adjustment for age, sex, socioeconomic status, smoking, leisure time physical activity, consumption of fruit and vegetables, and consumption of alcohol. Stratified analyses were made for different age groups, for men and women, for different socioeconomic groups, and for different engagement in leisure time physical activity. All analyses were conducted using the statistical program IBM SPSS Statistics V.21.

\section{Ethical considerations}

The baseline study of WOLF was approved by the Ethics Committee at Karolinska Institutet, Stockholm (\#92-198). All participation in the study was voluntary and with informed consent from the respondents. The record linkages of baseline data with the National Patient Register and the Cause of Death Register were approved by the Regional Ethical Review board in Stockholm (\#2006/257-31).

\section{RESULTS}

In total, 9961 people, 6849 men and 3112 women, without a history of myocardial infarction were followed during a mean follow-up time of 13.1 years (47 days16.9 years). During the follow-up time, 249 cases, both fatal and nonfatal, of myocardial infarction were registered, 223 among men and 26 among women. Table 1 shows baseline characteristics of the study participants in total, and divided by the three levels of occupational physical activity. Most of the participants in the study belonged to OPA $1 \quad(n=4997)$. The other two groups, OPA $2 \quad(n=2568)$ and OPA $3 \quad(n=2396)$, were quite similar regarding number of participants. The mean age at baseline was 42.7 (range 19-70) years. A clear difference was seen in the distribution of men and women in the different levels of OPA, with the lowest proportion of women in OPA 3. As expected, there was also a clear difference in socioeconomic status between the three levels of OPA. Almost $90 \%$ of the participants in OPA 3 were manual workers and only $0.9 \%$ were professionals. In contrast, only $19 \%$ in OPA 1 were manual workers.
Some differences in lifestyle factors in the three levels of occupational physical activity were seen at baseline. For example, the highest proportion of current smokers was observed in OPA 3, while the highest proportion of leisure time physical activity was found in OPA 1. An alternative categorisation of occupational physical activity is presented in online supplementary tables S1 and S2, where the group with sedentary jobs in combination with lifting/carrying was treated as a separate category.

The results of the Cox proportional hazard regressions with occupational physical activity as exposure and myocardial infarction as outcome are shown in table 2. In model 1, adjusted for age, the HR for OPA 2 was 1.29 (95\% CI 0.96 to 1.72), the corresponding HR for OPA 3 was 1.20 (95\% CI 0.87 to 1.64 ), with OPA 1 as the reference category. Adjusting for age, sex and socioeconomic status (model 3) resulted in an HR of 1.13 (95\% CI 0.83 to 1.54 ) for OPA 2 and HR of 0.86 (95\% CI 0.59 to 1.24) for OPA 3 compared with OPA 1. Adjustment for lifestyle factors (model 4) did not alter the HRs in any major way. It might be argued that socioeconomic status should not be adjusted for since it may lead to overadjustment; model 5 is therefore without adjustment for socioeconomic status. Table 2 also contains analyses restricted to those working 35 hours per week or more $(n=9058)$. In general, the results from these analyses were very similar to the results based on the total sample. A significant increased HR was seen for OPA 2 compared with OPA 1 in model 1, HR 1.36 (95\% CI 1.00 to 1.86 ), but after adjusting for age, sex and socioeconomic status (model 3), the HR for OPA 2 was attenuated to 1.18 ( $95 \%$ CI 0.85 to 1.63 ).

Results from stratified analyses, adjusted age, sex and socioeconomic status, where applicable, are shown in table 3. The HRs for the different levels of occupational physical activity in relation to myocardial infarction indicate no major differences between men and women. However, the CIs for women compared with men are wider, indicating greater uncertainty due to few cases. Stratified analysis for different socioeconomic groups shows a tendency towards decreased risk for professionals in OPA 2, compared with manual workers and low and intermediate manual workers in OPA 2. However, these analyses are based on subgroups with few participants, which must be considered. Stratifying for different levels of leisure time physical activity showed a tendency towards reduced risk for participants who are physically active both during work and leisure time, but the result was not statistically significant. When stratifying for age, a reduced risk for myocardial infarction was observed for young participants, aged $<45$, in OPA 3 (HR $0.37,95 \%$ CI 0.17 to 0.84 ). A joint effect analysis between occupational physical activity and leisure time physical activity, in relation to the risk of myocardial infarction, was made as a supplementary analysis (see online supplementary table S3). The result showed a significant increased risk for myocardial infarction for people with a lot of standing and walking at 
Table 1 Baseline characteristics of study participants by occupational physical activity

\begin{tabular}{|c|c|c|c|c|c|}
\hline & $\begin{array}{l}\text { Total } \\
\mathrm{n}=9961\end{array}$ & $\begin{array}{l}\text { OPA } 1 * \\
n=4997\end{array}$ & $\begin{array}{l}\text { OPA } 2 \dagger \\
n=2568\end{array}$ & $\begin{array}{l}\text { OPA } 3 \ddagger \\
n=2396\end{array}$ & p Value§ \\
\hline \multicolumn{6}{|l|}{ Age } \\
\hline Mean (SD) & $42.7(10.7)$ & $43.2(10.1)$ & $43.0(10.9)$ & $41.5(11.4)$ & $<0.001$ \\
\hline$<45$ years, $n(\%)$ & $5306(53.3)$ & $2602(52.1)$ & $1322(51.5)$ & $1382(57.7)$ & $<0.001$ \\
\hline $45-54$ years, $n(\%)$ & $3164(31.8)$ & $1701(34.0)$ & 820 (31.9) & $643(26.8)$ & \\
\hline$\geq 55$ years, $n(\%)$ & $1491(15.0)$ & $694(13.9)$ & 426 (16.6) & $371(15.5)$ & \\
\hline \multicolumn{6}{|l|}{ Sex, n (\%) } \\
\hline Men & $6849(68.8)$ & $3075(61.5)$ & $1751(68.2)$ & $2023(84.4)$ & $<0.001$ \\
\hline Women & $3112(31.2)$ & $1922(38.5)$ & 817 (31.8) & 373 (15.6) & \\
\hline Myocardial infarction during follow-up, n (\%) & $249(2.5)$ & $116(2.3)$ & $74(2.9)$ & $59(2.5)$ & 0.33 \\
\hline \multicolumn{6}{|l|}{ Socioeconomic status, $\mathrm{n}(\%)$} \\
\hline Manual workers & 4372 (43.9) & 965 (19.3) & $1257(49.0)$ & 2150 (89.8) & $<0.001$ \\
\hline Low and intermediate non-manual workers & 4334 (43.5) & 3008 (60.3) & 1102 (42.2) & $224(9.4)$ & \\
\hline Professionals & $1246(12.5)$ & $1017(20.4)$ & $208(8.1)$ & $21(0.9)$ & \\
\hline \multicolumn{6}{|l|}{ Smoking, n (\%) } \\
\hline Never smoked & 4647 (47.8) & 2435 (49.6) & $1209(48.1)$ & $1003(43.5)$ & $<0.001$ \\
\hline Former smoker & $2872(29.5)$ & $1500(30.6)$ & $728(29.0)$ & $644(27.9)$ & \\
\hline Current smoker & $2207(22.7)$ & $972(19.8)$ & $575(22.9)$ & $660(28.6)$ & \\
\hline \multicolumn{6}{|l|}{ Leisure time physical activity, $\mathrm{n}(\%)$} \\
\hline Never or seldom & 2479 (24.9) & $1181(23.7)$ & $609(23.7)$ & $689(28.9)$ & $<0.001$ \\
\hline Sometimes & 3823 (38.4) & 1787 (35.8) & 1019 (39.7) & $1017(42.6)$ & \\
\hline Regularly & $3645(36.6)$ & $2025(40.6)$ & $938(36.6)$ & $682(28.6)$ & \\
\hline \multicolumn{6}{|l|}{ Consumption of fruit, $\mathrm{n}(\%)$} \\
\hline One piece or more per day & $6160(63.1)$ & $3130(63.5)$ & $1618(64.2)$ & $1412(60.8)$ & 0.03 \\
\hline \multicolumn{6}{|l|}{ Consumption of vegetables, $n(\%)$} \\
\hline One portion or more per day & $3250(34.1)$ & $1895(39.1)$ & 792 (32.3) & $563(25.3)$ & $<0.001$ \\
\hline \multicolumn{6}{|l|}{ Consumption of alcohol, $n(\%)$} \\
\hline Non-drinker & $490(5.0)$ & $185(3.8)$ & $147(5.8)$ & $158(6.8)$ & $<0.001$ \\
\hline Moderate & 8554 (87.7) & $4408(89.5)$ & 2231 (88.7) & $1915(83.0)$ & \\
\hline Intermediate & $312(3.2)$ & $158(3.2)$ & $64(2.5)$ & $90(3.9)$ & \\
\hline Heavy & $394(4.0)$ & $176(3.6)$ & $73(2.9)$ & $145(6.3)$ & \\
\hline
\end{tabular}

work combined with never or seldom being physical active during leisure time.

\section{DISCUSSION}

In this study, we found no significant associations between occupational physical activity and myocardial infarction, neither when looking at participants with substantial standing and walking at work, nor when looking at participants with lifting or carrying at work, compared with participants who were seated most of their working day. Based on the results from this study, occupational physical activity does not seem to have the same association with myocardial infarction which is seen for leisure time physical activity. The hypothesis that occupational physical activity has a protective effect against myocardial infarction could not be confirmed in this study. Neither do the results from this study support the theory that high levels of occupational physical activity would increase the risk of myocardial infarction.
A restriction to full-time workers was made in order to see if the association between occupational physical activity and myocardial infarction would be stronger in this group. The results from the analyses adjusted for age, showed significant increased risk of myocardial infarction for the participants with substantial standing and walking at work. However, this association was attenuated and no longer statistically significant after adjusting for other traditional risk factors as sex, socioeconomic status and lifestyle factors. In general, the results from the restricted analyses were similar to the results based on the total sample.

Other studies of occupational physical activity and myocardial infarction have shown diverse results. A significant increased risk of myocardial infarction for men with moderate levels of occupational physical activity was, for example, observed in the study by Holtermann et $a l^{15}$ in the Copenhagen City Heart Study. Unlike this study, they used a combination of baseline and follow-up measures after 5 years in their categorisation of 


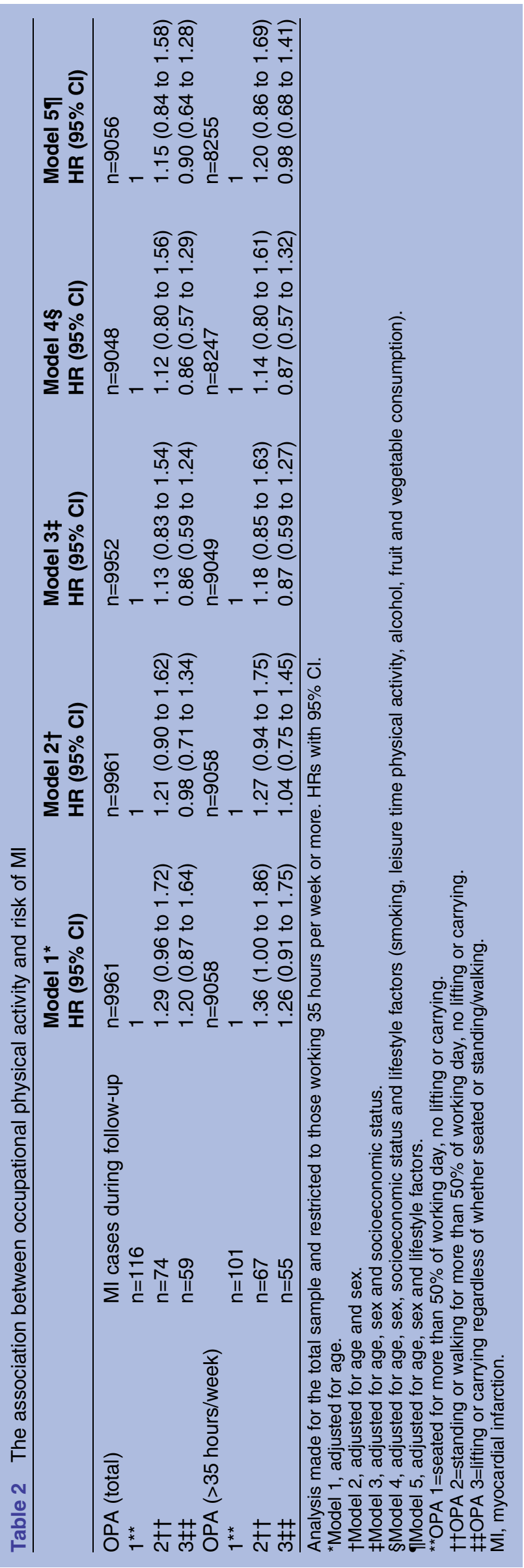

occupational physical activity. Furthermore, in a study by Allesøe $e t a l,{ }^{14}$ increased risk was noted for women with high levels of physical activity at work. In contrast to this study where a variety of occupations are included, their study only included nurses.

A significant reduced risk for myocardial infarction was noted for men and women with moderate-to-high levels of occupational physical activity in a Finnish study. ${ }^{16}$ They were using quite similar categorisation as in this study. A difference, though, is that they started their data collection 20 years earlier than our study. The two studies differ with regard to the number of participants in the highest level of occupational physical activity, the Finnish study having higher numbers in this category. The differences in results seen between the two studies may reflect changes over time regarding both occupational physical activity and physical activity in general.

In the guidelines from the WHO regarding physical activity, ${ }^{18}$ the importance of a non-sedentary lifestyle is emphasised, in order to protect diseases. However, in a recent study by Møller et $a l^{21}$ no differences were seen between employees with sedentary and non-sedentary work regarding the risk of ischaemic heart disease. It has been proposed that leisure time physical activity and occupational physical activity might have different effects on the cardiovascular system, with leisure time physical activity leading to a training effect on the heart and occupational physical activity leading to an overload on the cardiovascular system. ${ }^{22}$

A factor that might affect the risk of myocardial infarction is the participants' level of physical fitness. It has previously been shown that high levels of occupational physical activity do not seem to improve physical fitness. ${ }^{23}{ }^{24}$ This could be understood from the idea that occupational physical activity in most cases does not increase the heart rate enough to improve the fitness level, and therefore does not have a positive effect on the cardiovascular system. Research where a combination of high levels of occupational physical activity and moderate-to-high levels of leisure time physical activity has been studied has resulted both in increased ${ }^{25}$ and decreased $^{26}$ risk of ischaemic heart disease. When looking at the baseline characteristics of participants in this study, there is a larger proportion taking part in leisure time physical activity in OPA 1 , which decreases in OPA 2 and is smallest in OPA 3. Explanations for this may involve that high levels of occupational physical activity lead to fatigue in leisure time, with little energy left to take part in exercise. Other possible explanations may involve socioeconomic differences between groups and, thereby, differences in health behaviour.

Stratifying for different age groups resulted in a significantly reduced risk for participants aged younger than 45 years, with work including lifting or carrying. One possible explanation for these findings might be the, in general, higher fitness level seen in younger people, which may allow for a higher level of occupational 
Table 3 The association between occupational physical activity and risk of myocardial infarction

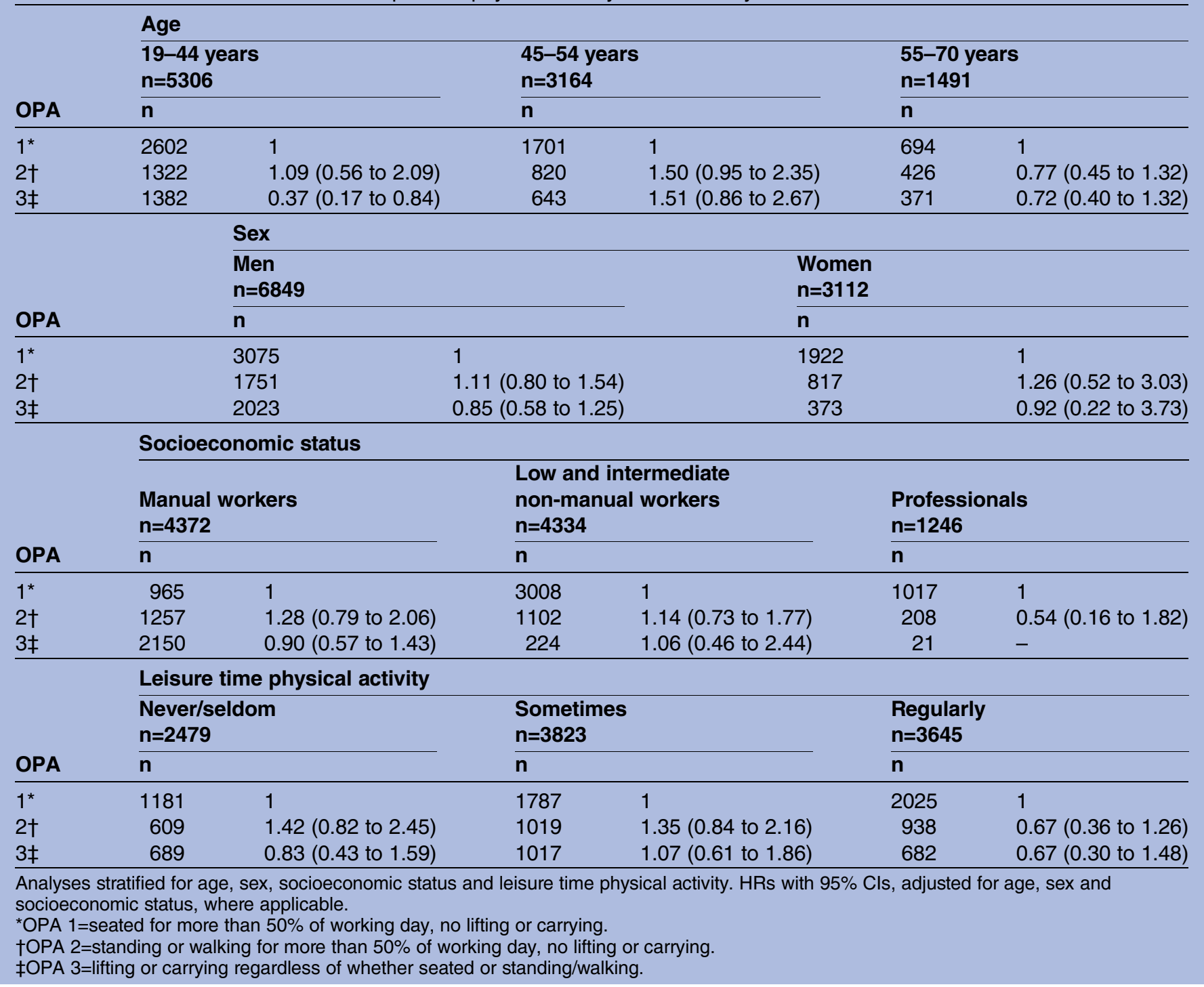

physical activity. For the middle-aged, 45-54 years, no statistically significant results were seen. Compared with the younger participants, the results for this group rather showed a tendency towards increased risk of myocardial infarction for work including substantial standing and walking. This might have to do with declining functional reserve capacity with older ages. ${ }^{27}$ In contrast to the results from the middle-aged group, the results from the group of the oldest participants do not show the same tendency towards increased risk, as seen for the middle-aged. Here, theories about 'the healthy worker, ${ }^{28}$ might be part of the explanation. In general, all the results from the stratified analyses must be interpreted with caution, due to the few participants in some of the analysed subgroups, leading to low precision in estimates and wide CIs, and hence low power to detect a true association.

A strength of this study is the high response rate, together with the distribution between different socioeconomic groups, which increases the validity of this study and also the ability to generalise the results from this study to the Swedish population as well as to other populations with similarities in working conditions. Data on myocardial infarction were obtained from the National Patient Register and the Cause of Death Register in Sweden. The proportion of cases of myocardial infarction identified by the registers has been found to be between $77 \%$ and $91.5 \%$, which implies high validity and little loss of follow-up for these data. ${ }^{29}$ In this study, only cases of myocardial infarction were used; extension to other diagnoses of ischaemic heart diseases would probably have led to more cases and higher power. However, we wanted to use the specific and welldefined outcome of myocardial infarction in this analysis.

One limitation of this study is that only data from the baseline are used regarding the participants' levels of occupational physical activity. Participants may have 
changed the exposure category during the time of follow-up. Given that a true association exists between occupational physical activity and myocardial infarction, change of exposure category might have attenuated the association in this study. A follow-up of the participants' level of occupational physical activity would therefore have further increased the validity of this study. Another limitation is that the data regarding occupational physical activity is self-reported from the participants and the questions may be considered rather unspecific. For example, the predefined cut-off for sitting or standing more or less than $50 \%$ of the working day was used in our study. This may not necessarily be the best way of defining being sedentary versus physically active at work. Other ways of assessing occupational physical activity are, for example, used by Krause et al. ${ }^{13}$ They interviewed the study participants about their physical activity at work and how many minutes they spent in different activities. Based on these interviews, the participants energy expenditure were calculated. A more objective measurement is tested by Skotte et $a \vec{l}^{\beta 0}$ using triaxial accelerometers for detection of physical activity. An objective assessment of occupational physical activity would have been preferable, but is often not feasible to include in large-scale epidemiological studies, as this would require extensive resources. These limitations regarding assessment of occupational physical activity also largely apply to the assessment of leisure time physical activity in the WOLF study.

\section{Conclusion}

No significant associations between occupational physical activity and the risk of myocardial infarction was observed in this prospective cohort study of 9961 employees in the total study population. A significant reduced risk was seen for participants younger than 45 years with work including lifting and carrying, but this result must be interpreted with caution, due to the few participants in the stratified analyses. Based on the results from this study, occupational physical activity in general does not seem to be enough for reducing the risk of myocardial infarction, which is an important message to people with high levels of occupational physical activity.

Contributors LA, AK and PJMW were responsible for the baseline data collection. AMJ and EIF were responsible for the conception and design of this study. AMJ drafted the first version of the manuscript. All authors interpreted the data and revised the manuscript critically for important intellectual content. They also read and approved the final version of the manuscript.

Funding This research received no specific grant from any funding agency in the public, commercial or not-for-profit sectors.

Competing interests None declared.

Ethics approval Ethics Committee at Karolinska Institutet, Stockholm (\#92-198) Regional Ethical Review board in Stockholm (\#2006/257-31).

Provenance and peer review Not commissioned; externally peer reviewed.
Data sharing statement No additional data are available.

Open Access This is an Open Access article distributed in accordance with the Creative Commons Attribution Non Commercial (CC BY-NC 4.0) license, which permits others to distribute, remix, adapt, build upon this work noncommercially, and license their derivative works on different terms, provided the original work is properly cited and the use is non-commercial. See: http:// creativecommons.org/licenses/by-nc/4.0/

\section{REFERENCES}

1. Lozano R, Naghavi M, Foreman K, et al. Global and regional mortality from 235 causes of death for 20 age groups in 1990 and 2010: a systematic analysis for the Global Burden of Disease Study 2010. Lancet 2012;380:2095-128.

2. Murray CJ, Vos T, Lozano R, et al. Disability-adjusted life years (DALYs) for 291 diseases and injuries in 21 regions, 1990-2010: a systematic analysis for the Global Burden of Disease Study 2010. Lancet 2012;380:2197-223.

3. Nocon M, Hiemann T, Müller-Riemenschneider F, et al. Association of physical activity with all-cause and cardiovascular mortality: a systematic review and meta-analysis. Eur J Cardiovasc Prev Rehabil 2008;15:239-46.

4. Wannamethee SG, Shaper AG. Physical activity in the prevention of cardiovascular disease: an epidemiological perspective. Sports Med 2001;31:101-14.

5. Perk J, De Backer G, Gohlke H, et al. European Guidelines on cardiovascular disease prevention in clinical practice (version 2012): the Fifth Joint Task Force of the European Society of Cardiology and other societies on cardiovascular disease prevention in clinical practice (constituted by representatives of nine societies and by invited experts). Int J Behav Med 2012;19:403-88.

6. Yusuf S, Hawken S, Ounpuu S, et al. Effect of potentially modifiable risk factors associated with myocardial infarction in 52 countries (the INTERHEART study): case-control study. Lancet 2004;364:937-52

7. World Health Organization. Global status report on noncommunicable diseases 2014: "attaining the nine global noncommunicable diseases targets; a shared responsibility". Geneva: World Health Organization, 2014.

8. Sofi F, Capalbo A, Cesari F, et al. Physical activity during leisure time and primary prevention of coronary heart disease: an updated meta-analysis of cohort studies. Eur $J$ Cardiovasc Prev Rehabil 2008;15:247-57.

9. Fransson E, De Faire U, Ahlbom A, et al. The risk of acute myocardial infarction: interactions of types of physical activity. Epidemiology 2004;15:573-82.

10. Held C, Iqbal R, Lear SA, et al. Physical activity levels, ownership of goods promoting sedentary behaviour and risk of myocardial infarction: results of the INTERHEART study. Eur Heart $J$ 2012;33:452-66.

11. Li J, Loerbroks A, Angerer P. Physical activity and risk of cardiovascular disease: what does the new epidemiological evidence show? Curr Opin Cardiol 2013;28:575-83.

12. Hu GC, Chien KL, Hsieh SF, et al. Occupational versus leisure-time physical activity in reducing cardiovascular risks and mortality among ethnic Chinese adults in Taiwan. Asia Pac J Public Health 2014;26:604-13.

13. Krause N, Brand RJ, Arah OA, et al. Occupational physical activity and 20-year incidence of acute myocardial infarction: results from the Kuopio Ischemic Heart Disease Risk Factor Study. Scand $J$ Work Environ Health 2015;41:124-39.

14. Allesøe K, Holtermann A, Aadahl M, et al. High occupational physical activity and risk of ischaemic heart disease in women: the interplay with physical activity during leisure time. Eur J Prev Cardiol 2015;22:1601-8.

15. Holtermann A, Marott JL, Gyntelberg F, et al. Occupational and leisure time physical activity: risk of all-cause mortality and myocardial infarction in the Copenhagen City Heart Study. A prospective cohort study. BMJ Open 2012;2:e000556.

16. Hu G, Tuomilehto J, Borodulin K, et al. The joint associations of occupational, commuting, and leisure-time physical activity, and the Framingham Risk Score on the 10-year risk of coronary heart disease. Eur Heart J 2007;28:492-8.

17. Li J, Siegrist J. Physical activity and risk of cardiovascular diseasea meta-analysis of prospective cohort studies. Int $J$ Environ Res Public Health 2012;9:391-407.

18. World Health Organization. Global recommendations on physical activity for health. Geneva: World Health Organization, 2010. 
19. Alfredsson L, Hammar N, Fransson E, et al. Job strain and major risk factors for coronary heart disease among employed males and females in a Swedish study on work, lipids and fibrinogen. Scand J Work Environ Health 2002;28:238-48.

20. Statistiska Centralbyrån. Socioekonomisk indelning (SEI). Swedish socioeconomic classification. Reports on Statistical Co-ordination 1982. Vol 4. 1982.

21. Møller SV, Hannerz H, Hansen AM, et al. Multi-wave cohort study of sedentary work and risk of ischemic heart disease. Scand J Work Environ Health 2016;42:43-51.

22. Krause N. Physical activity and cardiovascular mortalitydisentangling the roles of work, fitness, and leisure. Scand J Work Environ Health 2010;36:349-55.

23. Holtermann A, Mortensen OS, Søgaard K, et al. Risk factors for ischaemic heart disease mortality among men with different occupational physical demands. A 30-year prospective cohort study. BMJ Open 2012;2:e000279.

24. Nygård $\mathrm{CH}$, Luopajärvi T, Ilmarinen J. Musculoskeletal capacity and its changes among aging municipal employees in different work categories. Scand J Work Environ Health 1991;17(Suppl 1):110-17.
25. Clays E, De Bacquer D, Janssens $\mathrm{H}$, et al. The association between leisure time physical activity and coronary heart disease among men with different physical work demands: a prospective cohort study. Eur J Epidemiol 2013;28:241-7.

26. Holtermann A, Mortensen OS, Burr $\mathrm{H}$, et al. The interplay between physical activity at work and during leisure time-risk of ischemic heart disease and all-cause mortality in middle-aged Caucasian men. Scand J Work Environ Health 2009;35: 466-74.

27. Goldspink DF. Ageing and activity: their effects on the functional reserve capacities of the heart and vascular smooth and skeletal muscles. Ergonomics 2005;48:1334-51.

28. Shah D. Healthy worker effect phenomenon. Indian J Occup Environ Med 2009;13:77-9.

29. Ludvigsson JF, Andersson E, Ekbom A, et al. External review and validation of the Swedish National Inpatient Register. BMC Public Health 2011;11:450.

30. Skotte J, Korshøj M, Kristiansen J, et al. Detection of physical activity types using triaxial accelerometers. $J$ Phys Act Health 2014;11:76-84. 